\title{
Automation of quality control of digital topographic maps at the scale 1:50 000 of the Main State Topographic Map in Ukraine
}

\author{
Nadiia Lazorenko-Hevel ${ }^{\mathrm{a}, *}$, Yurii Karpinskyi ${ }^{\mathrm{a}, *}$, Danylo Kin ${ }^{\mathrm{a}, *}$, Olexander Lets ${ }^{\mathrm{b}}$ \\ ${ }^{a}$ Department of Geoinformation system and photogrammetry, Kyiv National University of Construction and Architecture, \\ 31 Povitroflotsky Ave, Kyiv,03037,Ukraine,nadiialg@gmail.com, karpinskyiyurii@gmail.com, kondanil24@gmail.com \\ ${ }^{b}$ Research Institute of Geodesy and Cartography 69, Velika Vasylkivska Str., Kyiv, 03150, Ukraine, letsolexandr@gmail.com \\ * Corresponding author
}

\begin{abstract}
This research examines the problem of automation of quality control of digital topographic maps at the scale 1:50 000 of the Main State Topographic Map in Ukraine for the creation and maintaining the seamless topographic database for national needs, which is located on the Geoportal to ensure the development of the National Spatial Data Infrastructure (NSDI) in Ukraine. The authors determined stages of quality control of digital topographic maps at the scale of 1:50 000 for the automation one according to ISO 19157:2013 Geographic Information - Data quality. The realized automated quality control of geodatabases of updated digital topographic maps at a scale of 1:50 000 provides high speed and quality of validation: validation of quality data elements; validation of quality metadata; validation of positional accuracy. The software package "Validate" was developed for automation quality control geodatabases of digital topographic maps at the scale of 1:50 000 using the Python programming language to verify logical consistency, compliance with the rules of topological relationships between features on the map, availability and content of metadata. The "Validate" can be used for automation quality control geodatabase for any map scale, performing setting according to the requirements of the geospatial models.
\end{abstract}

Keywords: quality control, topographic mapping, validation

\section{Introduction}

The seamless topographic database (hereinafter - TDB) of the Main State Topographic Map of the scale 1:50 000 is being created for the first time in Ukraine and it will become the Core Reference Dataset for the development of National Spatial Data Infrastructure (The NSDI Law of Ukraine, 13.04.2020). The input data of the seamless topographic database are the updated digital topographic maps of the scale 1:50 000. The urgent need for the creation of TDB formulates the need to increase the intellectual level of creation spatial data of topographic features and led to the emergence of new requirements for creating (updating) digital topographic maps as initial data for the seamless topographic database (Karpinskyi and Lazorenko-Hevel, 2020).

The process of creation (updating) digital topographic maps of the scale 1:50 000 have some peculiarities: automated creation of new virtual and associated features, use rules of the digital description of topographic features and rules of topological relations between features of a digital topographic map, providing of automated quality control of updated digital topographic maps, development the Geoportal project monitoring and support system for production process automation, control of implementation and simplification of access to information exchange between project participants.

The peculiarities of creation (updating) digital topographic maps of the scale 1:50 000 need the development of modern automated quality control of the updated geodatabases of the digital topographic maps.

\section{Methodology}

\subsection{Study area}

The quality control of geospatial data in the conditions of geospatial data infrastructure development is researched in (Jakobsson and Tsoulos, 2007; Hunter et al., 2009; Devillers et al., 2010; Docan, 2013; Cetl et al., 2019). Software solutions for automation of quality control of geospatial data for topographic databases and land administration systems are given in (Chen et al., 2007; Siejka et al., 2013; Bielecka et al., 2014; de França, 2018). Aspects of data quality in topographic databases were considered by the authors (Jakobsson, 2006; Martinez-Llario et al., 2017; Ślusarski and Siejka, 2017; Karpinskyi and Lazorenko-Hevel, 2018; Karpinskyi and Lazorenko-Hevel, 2020). Topological consistency, as an element of data quality, was mathematically described in (Hoel et al, 2003; Karpinskyi, 2015). The peculiarities of quality control of geospatial data were determined:

- the quality control of geospatial data must correspond to the requirements of the standard ISO 19157:2013 Geographic Information - Data quality (ISO, 2013);

- the quality of the metadata must correspond to the requirements of the national standard of Ukraine DSTU ISO/TS 19139:2017 Geographic 
information - Metadata - XML schema implementation (DSTU ISO, 2017);

- the automation of quality control is possible in commercial geographic information systems and open-source;

- the automation of all stages of quality control of geospatial data has not been implemented, except for visual verification, which is performed manually by cartographers.

The purpose of the article is the automation of quality control of digital topographic maps at the scale 1:50 000 of the Main State Topographic Map in Ukraine.

\subsection{Software package development}

The authors determined stages of quality control of digital topographic maps at the scale of 1:50 000 for the automation one according to ISO 19157:2013 Geographic Information - Data quality (Figure 1).

The quality control of the updated digital topographic map consists of the following stages:

1) Validation of Completeness files of digital topographic maps of the scale 1:50 000;

2) Validation of Quality Data Elements;

3) Validation of Quality Metadata;

4) Validation of Positional Accuracy;

5) Verification of the consistency of information about the topographic features;

6) Determine the output of the data quality evaluation.

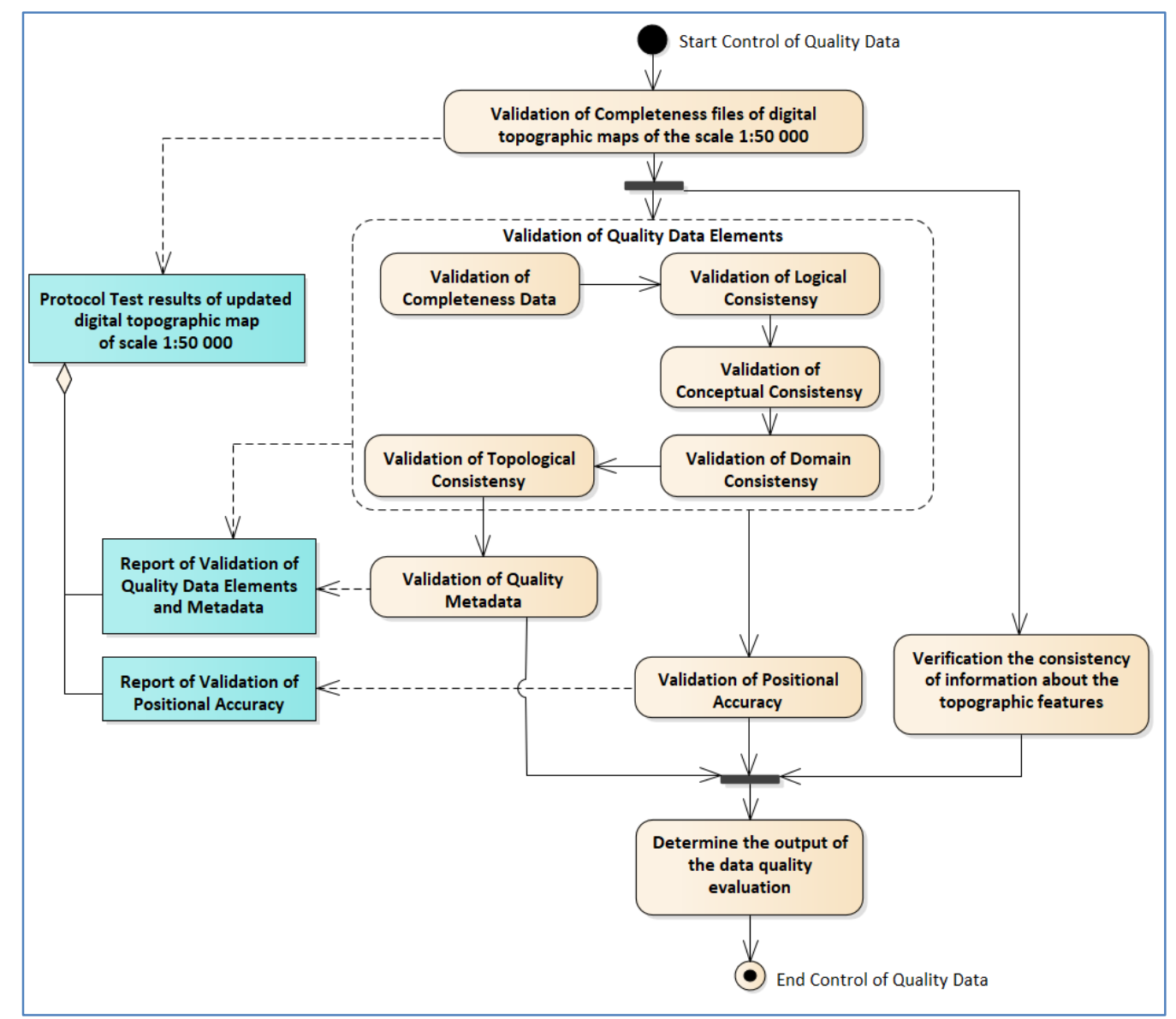

Figure 1. The diagram activities of quality control of updated digital topographic maps of the scale 1:50 000.

The main elements of the quality of topographic data and the quality of metadata include:

1) Completeness Data is defined as the presence and absence of features, their attributes and relationships;

2) Logical consistency is the degree of adherence to logical rules of data structure that are defined by the rules of the digital description of topographic data; the correspondence of the attributes values of the value domains defined in the feature catalogue; topological consistency of geometric models of topographic features and their descriptions;

3) Metadata quality is the availability and content of metadata in the geodatabase of the updated digital topographic map;

4) Positional accuracy is the accuracy of topographic features is defined as the accuracy of the position of features within a spatial reference 
The logical consistency of topographic data is assessed by indicators:

- conceptual consistency is the adherence to rules of conceptual schema and structure and relationships according to the rules for the creation (updating) digital topographic maps at the scale of 1:50 000);

- domain consistency is the adherence of attributes values of topographic features to the value domains;

- format consistency is the degree to which the geodatabase with the updated digital topographic map is stored following the physical structure of the dataset;

- topological consistency is the correctness of the explicitly encoded topological characteristics of the features of the digital topographic maps. Topological consistency is determined both for geometric models of topographic features of the same type and for geometric models of topographic features of different types.

The Protocol Test report of the updated digital topographic map of the scale 1:50 000 is created as a result of quality control of the created (updated) digital topographic maps of the scale 1:50 000 .

\section{Results}

3.1 Methods of quality control of created (updated) digital topographic maps of the scale 1:50 000

The presence or absence of topographic features of the updated digital topographic map is performed by the executor visually by establishing a correspondence between the topographic features of the updated digital topographic map and the terrain features portrayed on the orthophoto.

Visual quality control of the updated digital topographic map is performed for:

- verification of completeness of materials;

- data completeness verification;

- verification of the consistency of information about the topographic features of the created sheet and adjacent sheets (summary of the map sheet on all sides of the frame).

- verification of edge matched adjacent updated topographic map sheets (Lazorenko-Hevel et al., 2020).

There are standard Check Geometry and Repair Geometry tools for verification conceptual consistency in ArcGIS.

These instruments control and correct the geometry of features, which will automatically detect geometry errors and correct some of them. The report is result of these tools that generated in tabular form with the specified classes of features and identifiers of features in which errors are detected.
Domain consistency verification is performed automatically according to the types of variables and the set of possible values of digital topographic map attributes specified in the Classifier of topographic features for the digital topographic map of the scale 1:50 000, and this is taken into account in the initial geodatabases (*.gdb).

The topological consistency, quality of metadata (availability and content of metadata) is verified using the software package "Validate".

\subsection{The software package "Validate"}

Quality control of created (updated) digital topographic maps at the scale of 1:50 000 is performed using ArcGIS software and the software package "Validate". This software package was developed by the authors and the staff of State Enterprise "Research Institute of Geodesy and Cartography" using the Python programming language to verify logical consistency, compliance with the rules of topological relationships between features on the map, availability and content of metadata.

The "Validate" consists of 141 topology rules (ESRI, 2012) between 45 feature classes of the digital topographic map of the scale 1:50 000 .

After using the software package "Validate" the geodatabase of digital topographic maps at the scale 1:50 000 has topology classes and temporary feature classes for validation topology consistency (Figure 2). Also, the created topology classes consist of three ranks: 1 rank - features with clear contours (networks of roads, streets, driveways, blocks and houses, power lines (voltage over $35 \mathrm{kV})$ ); 2 rank - bridges, sluices, drains, dams and channels, 3 - other features.

There are 3 error files were generated for point, line and polygonal features of the updated digital topographic map and the software quality control report as a result of using "Validate" (Figure 3).

The shapefiles with errors have the following structure:

- $\quad$ SHAPE - the shape of the feature marked as false;

- PROBLEM - short description of the error;

- CATEGORY - error category;

- EXCEPTION - the exception to the rules.

All these errors were corrected by the cartographers (Figure 4, Figure 5).

The errors were formed for each class of spatial features separately and the digital topographic map as a whole (Figure 6, Figure 7).

The software quality control report of the updated digital topographic map contains a table of possible errors of such categories:

- $\quad$ Critical - must be corrected;

- Important - must be corrected. In some cases, comments of this category may be permissible with the approval of the host cartographer; 


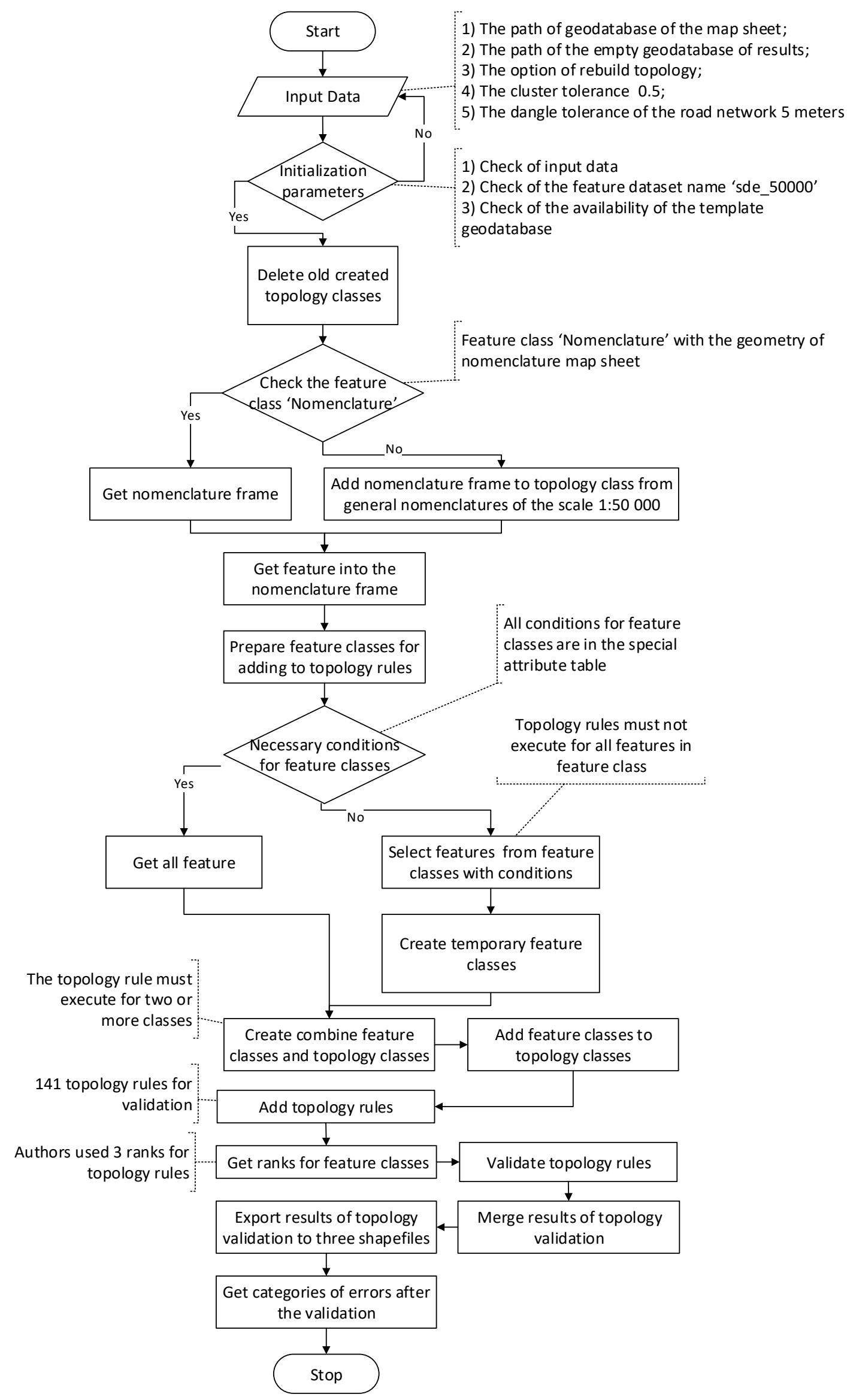

Figure 2. The block-schema of the "Validate". 
- Recommended - recommended for correction. Otherwise, comments in this category may be considered by the receiving cartographer as a mistake.

If the cartographer decided not to correct the error, then he/she indicated the reasons for such a decision in the column "Exception" and must prove the decision of exclusion.

Another general table of the number of types of errors was also formed.

The metadata quality control is characterized by the presence of mandatory, conditional and optional metadata elements (DSTU ISO, 2017). The mandatory, conditional and all other metadata elements are determined according to (DSTU ISO, 2017). The minimal set of the metadata elements is mandatory for filling by the cartographers.
The metadata validation is required to determine whether the required metadata elements are complete. The table of metadata errors will be formed after the validation of metadata with such structure:

- ERROR_TYPE - error type;

- PROBLEM - short description of the error;

- EXAMPLE - an example of data to fill in the appropriate parameter.

If all metadata are correct, the table of metadata errors will be empty in the software quality control report of the updated digital topographic map.

The document of the software quality control report in *.doc and *.pdf formats will be created after the report is generated by the "Validate" (Figure 8).

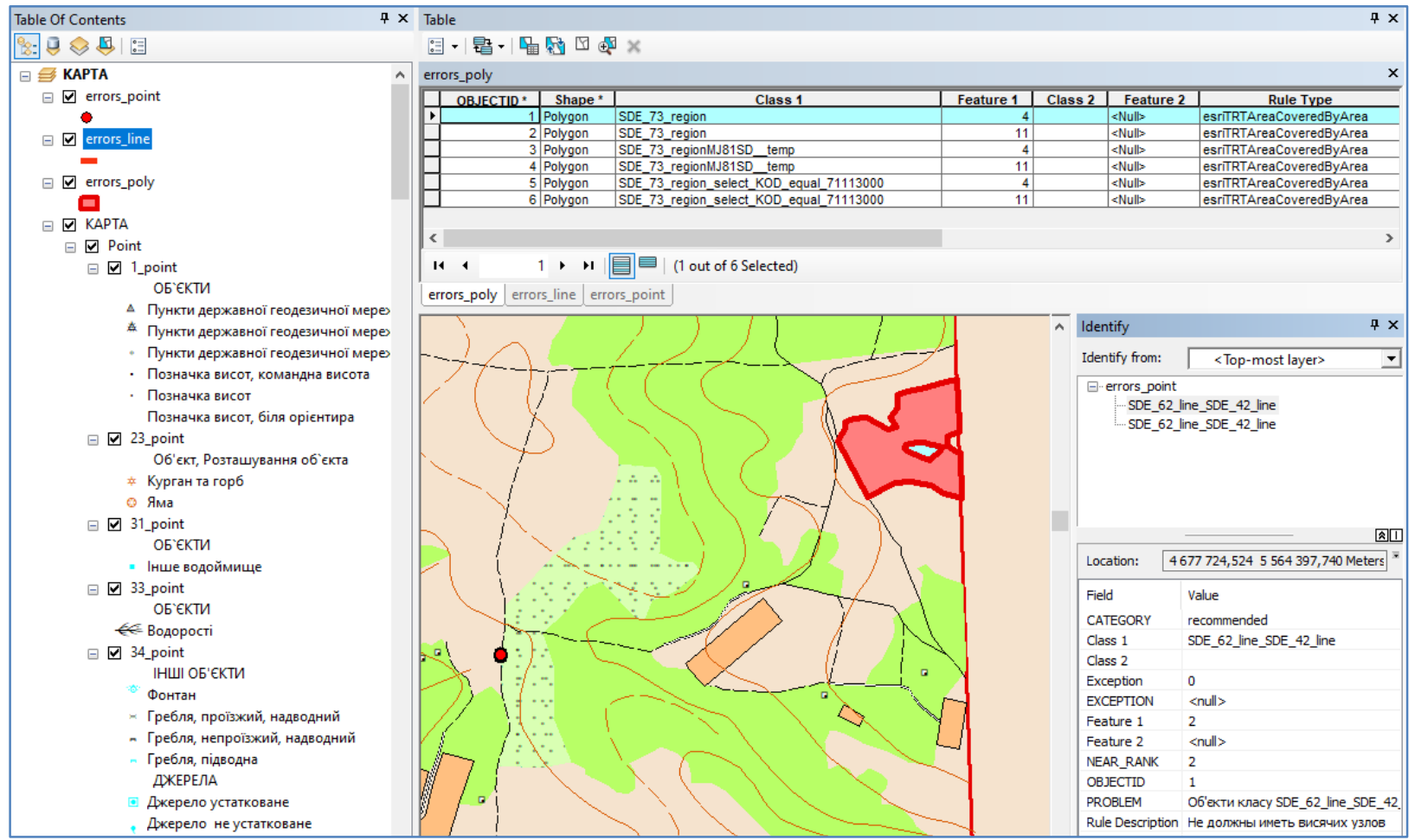

Figure 3. Three shape-files with errors of point, line and polygonal features.

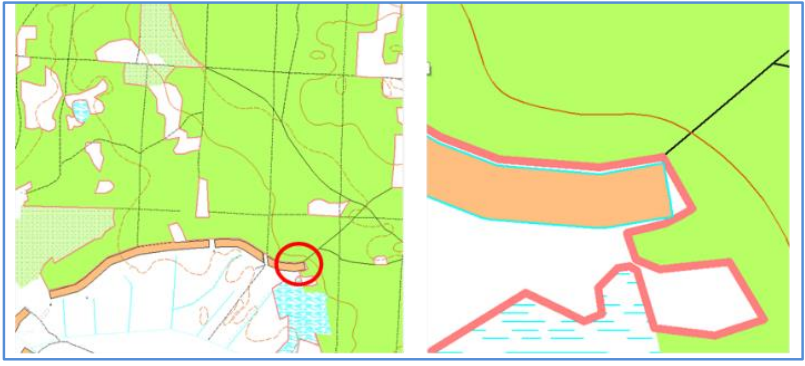

Figure 4. Example of topology rule: the boundary of the block (fill colour is orange) must be corresponding with the boundary of the forest (fill colour is green).

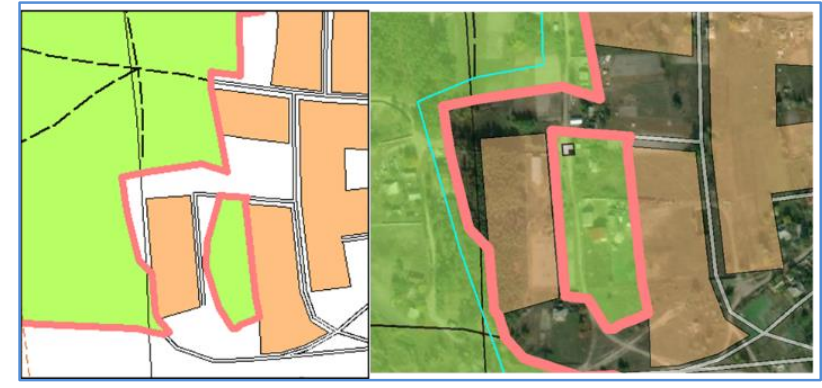

Figure 5. Example of topology rule: the boundary of the forest (fill colour is green) must be corresponding with the line of the street. 


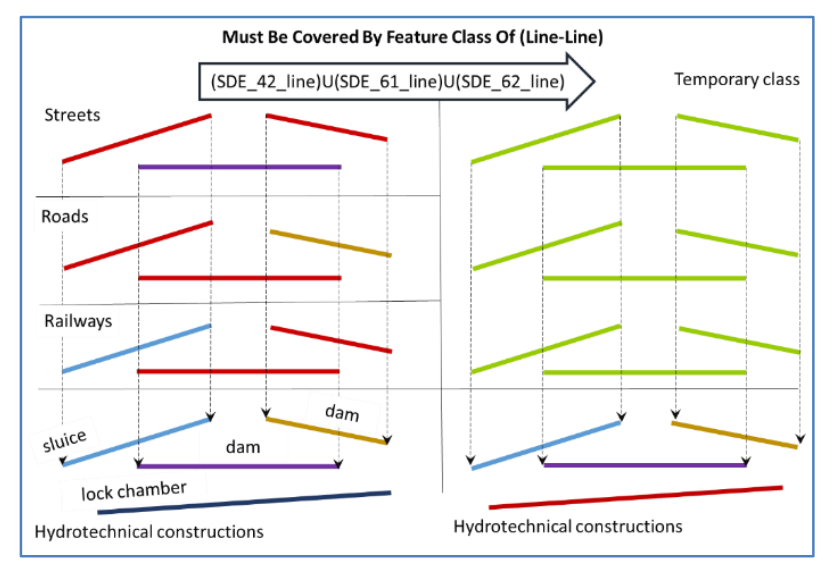

Figure 6. The example of topology rule "Must Be Covered By Feature Class of (Line-Line)" for two or more feature classes, where SDE_42_line - Streets, SDE_62_line - Roads, SDE_61_line - Railways.

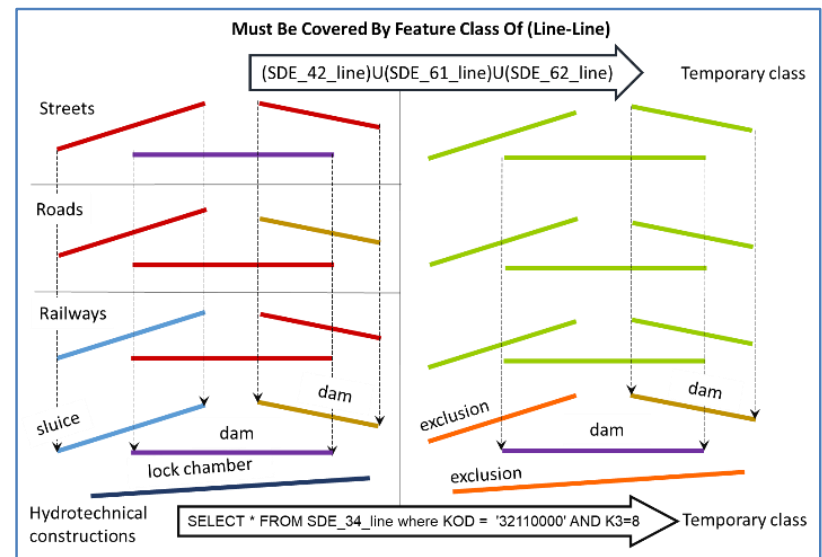

Figure 7. The example of topology rule "Must Be Covered By Feature Class of (Line-Line)" for two or more feature classes with exclusions, where SDE_42_line - Streets, SDE_62_line - Roads, SDE_61_line - Railways, SDE_34_line - Hydrotechnical constructions.

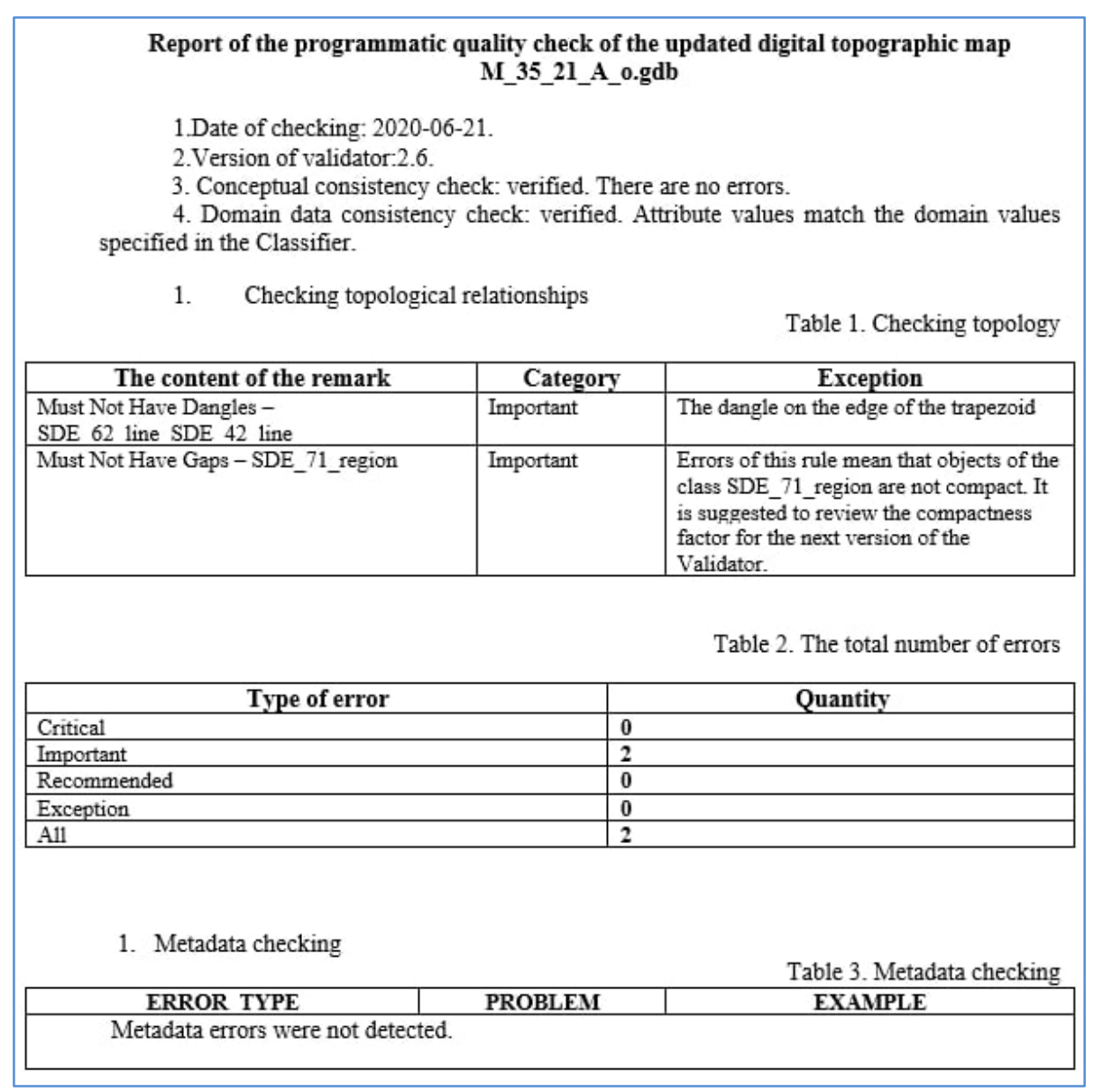

Figure 8. The example of the report of the programmatic quality check of the updated digital topographic map M_35_21_A_o.gdb.

\section{Conclusions}

The realized automated quality control of geodatabases of updated digital topographic maps at a scale of 1:50 000 provides high speed and quality of validation: validation of quality data elements; validation of quality metadata; validation of positional accuracy.
The implementation of such a quality control system during the creation (updating) digital topographic maps of the scale 1:50 000 ensured the high quality of the maps, which will become the initial data for the seamless topographic database of the Main State Topographic Map of Ukraine and public it on the Geoportal for the development of NSDI in Ukraine. 
The software package "Validate" can be used for automation quality control geodatabase for any map scale, performing setting according to the requirements of the geospatial models.

\section{References}

Bielecka, E., Leszczynska, M. and Halls, P. J. (2014). User perspective on geospatial data quality. Case study of the Polish Topographic Database. In Environmental Engineering. Proceedings of the International Conference on Environmental Engineering. ICEE (Vol. 9, p. 1). Vilnius Gediminas Technical University, Department of Construction Economics \& Property.

Chen, J., Liu, W., Li, Z., Zhao, R. and Cheng, T. (2007). Detection of spatial conflicts between rivers and contours in digital map updating. International Journal of Geographical Information Science, 21(10), 1093-1114.

Cetl, V., Ioannidis, C., Dalyot, S., Doytsher, Y., Felus, Y., Haklay, M. and Siriba, D. (2019). New Trends in Geospatial Information: The Land Surveyors Role in the Era of Crowdsourcing and VGI. International Federation of Surveyors (FIG): Copenhagen, Denmark, FIG PUBLICATION, (73).

Devillers, R., Stein, A., Bédard, Y., Chrisman, N., Fisher, P. and Shi, W. Thirty years of research on spatial data quality: achievements, failures, and opportunities. (2010). Transactions in GIS 14, 4, 387-400. doi:10.1111/j.1467-9671.2010.01212.x.

Docan, D. C. (2013). Spatial data quality assessment in GIS. In conference/DC Docan.-Antalya (pp. 105-112).

DSTU ISO, 2017. DSTU ISO/TS 19139:2017 Geographic information - Metadata - XML schema implementation (ISO/TS 19139:2007, IDT).

ESRI, 2012. ArcGIS 10.2 Geodatabase Topology Rules. Available online at http://resources.arcgis.com/en/ 10.2/01mm/pdf/topology_rules_poster.pdf accessed: 2021-04-04.

de França L. L. S. (2018). Topological validation of drainage network with QGIS. ANAIS $7^{\circ}$ SIMPÓSIO DE GEOTECNOLOGIAS NO PANTANAL Jardim MS. Embrapa Informática Agropecuária/INPE. p. 262- 273.

Hoel, E., Menon, S. and Morehouse, S. (2003, July). Building a robust relational implementation of topology. In International Symposium on Spatial and Temporal Databases (pp. 508-524). Springer, Berlin, Heidelberg.

Hoel, E., Menon, S. and Morehouse, S. (2003, July). Building a robust relational implementation of topology. In International Symposium on Spatial and Temporal Databases (pp. 508-524). Springer, Berlin, Heidelberg.

Hunter, G. J., Bregt, A. K., Heuvelink, G. B., De Bruin, S. and Virrantaus, K. (2009). Spatial data quality: problems and prospects. In Research trends in geographic information science (pp. 101-121). Springer, Berlin, Heidelberg.

ISO, 2013. ISO 19157: 2013 Geographic Information Data quality.
Jakobsson, A. (2006) On the Future of Topographic Base Information Management in Finland and Europe. Doctoral dissertation. Helsinki University of Technology, p.180. Available online at http://lib.tkk.fi/Diss/2006/isbn9512282062/isbn9512282 062.pdf accessed: 2021-04-04.

Jakobsson, A. and Tsoulos, L. (2007, August). The role of quality in spatial data infrastructures. In Proceedings of the 23rd International Cartographic Conference, Moscow, Russia, CD-ROM.

Karpinskyi Yu. (2015). Systemotekhnichni aspekty formuvannia topolohichnoho zemelno-kadastrovoho pokryttia. Visnyk heodezii ta kartohrafii. Kyiv, No 5-6 (98-99), P. 62-68.

Karpinskyi, Yu. and Lazorenko-Hevel, N. (2018). Application of topographic plans in the conditions of the development of national spatial data infrastructure, Mistobuduvannya ta terytorial'ne planuvannya, 68, $\mathrm{p}$. 712-724. Available online at http://nbuv.gov.ua/UJRN/ MTP_2018_68_85 accessed: 2021-04-04.

Karpinskyi, Yu. and Lazorenko-Hevel, N. (2020). Topographic mapping in the National Spatial Data Infrastructure in Ukraine. E3S Web of Conferences.171, p.1-6. https://doi.org/10.1051/e3sconf/202017102004.

Lazorenko-Hevel N., Kin D. and Karpinskyi Yu. (2020). Some aspects of the edge matching method of digital topographic maps in the scale of 1:50000 for creation the Main State Topographic Map. European Association of Geoscientists \& Engineers. Conference Proceedings, International Conference of Young Professionals «GeoTerrace-2020», Dec 2020, Volume 2020, p.1-5. https://doi.org/10.3997/2214-4609.20205758.

The Law of Ukraine "On the National Spatial Data Infrastructure" (bill No. 2370), 13.04.2020. Available online at http://w1.c1.rada.gov.ua/pls/zweb2/ webproc 34 ? $\mathrm{id}=\&$ pf $3511=67268 \&$ pf35401 $=525603$ accessed: 2021-04-04.

Martinez-Llario, J., Coll, E., Núñez-Andrés, M. and Femenia-Ribera, C. (2017). Rule-based topology system for spatial databases to validate complex geographic datasets. Computers \& Geosciences, 103, 122-132.

Siejka, M., Ślusarski, M. and Zygmunt, M. (2013). Correction of topological errors in geospatial databases. International Journal of Physical Sciences, 8(12), 498-507.

Ślusarski, M. and Siejka, M. (2017). Model of quality of data collected in the topographic database. International Multidisciplinary Scientific GeoConference: SGEM, 17, 595-602. 